\title{
Extracorporeal abdominal massage may help prevent recurrent bile duct stones after endo- scopic sphincterotomy
}

Authors

Institution
Naohito Uchida, Sae Hamaya, Miwa Tatsuta, Toshiaki Nakatsu

Department of Gastroenterology, Saint Martin's Hospital, Sakaide city, Kagawa ken, Japan submitted 5. January 2016 accepted after revision 30. May 2016

\section{Bibliography}

DOI http://dx.doi.org/

10.1055/s-0042-109774

Published online: 9.8.2016

Endoscopy International Open 2016; 04: E870-E873

(c) Georg Thieme Verlag KG Stuttgart · New York

E-ISSN 2196-9736

\section{Corresponding author}

\section{Naohito Uchida, MD, PhD}

Saint Martin's Hospital

1-4-13 Tani machi, Sakaide city

Kagawa ken

Japan 762-0033

Phone: +81 877465195

Fax: +81 877460595

naohito@kms.ac.jp
Background and study aims: Endoscopic sphincterotomy (EST) is effective, but recurrent bile duct stones are a common late complication. Because there are still no effective therapies for preventing this complication, some patients have experienced bile duct stone recurrence many times. We describe herein a method of abdominal massage to treat patients with prior cholecystectomy who have experienced recurrence of bile duct stones.

\section{Introduction}

$\checkmark$

Endoscopic sphincterotomy (EST) and stone extraction are safe and effective procedures for the treatment of bile duct stones [1,2] but bile duct stone recurrence after EST is a major problem [3] Because there are no effective therapies to prevent a recurrence of bile duct stones, some patients need repeated endoscopic treatment. The development of an effective method that can prevent the recurrence of bile duct stones is thus desired.

We treated 2 patients in whom the number of bile duct stone recurrences was greatly decreased by daily massage of the right hypochondrium. In 1 of the 2 patients, cholescintigraphy was performed to evaluate the influence of this abdominal massage on bile excretion. This is the first report that describes the utility of physical compression on the right hypochondrium to prevent bile duct stone recurrence after EST.

\section{Case Reports \\ $\nabla$}

\section{Patient 1}

A 68-year-old Japanese man with a history of cholecystectomy was admitted to our hospital because of right upper quadrant pain in April 1986. Endoscopic retrograde cholangiopancreatography $(E R C P)$ revealed $22.0 \times 2.5-\mathrm{cm}$ bile duct stones in a dilated common bile duct with a $2.5-\mathrm{cm}$ diameter.
Following EST with a large incision, the stones were extracted using a mechanical lithotripter. After that treatment, common bile duct stones recurred a total of 9 times: once each in 1987 and 1990, twice each in 1991 and 1992, once in 1994 and twice in 1995. Extraction of the stones was performed endoscopically each time.

Beginning in 1996, the patient performed extracorporeal abdominal massage on himself, mainly to the right hypochondrium while seated, once a day for approximately 10 minutes to 15 minutes, as instructed by us. The massage was performed on the right hypochondrium in a motion that was similar to kneading bread dough with the thick parts of the second to fifth fingers of the right hand. We instructed the patient to perform the abdominal massage as strongly as possible, imagining that the bile was being washed away into the duodenum by pressing the common bile duct. From the time that the patient started the daily massage regimen in 1996 and his death in 2005 due to another illness, he experienced only 1 more recurrence of bile duct stones, in 1998.

The clinical course of Patient 1 is shown in $\bullet$ Fig. 1. Cholescintigraphy was performed in March 2003 to objectively evaluate the effect of the daily massages, using the radiotracer $99 \mathrm{mTc}$-pyridoxyl-5-

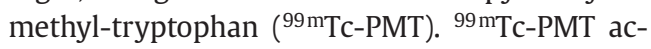
cumulates quickly in the liver, and is then rapidly excreted into the bile, even in the presence of liver disease $[4,5]$. For the cholescintigraphy, after his overnight fast, the patient was injected intravenously with $5 \mathrm{mCi}$ of $99 \mathrm{~m}$ Tc-PMT. Sequential images were obtained every 5 minutes for $90 \mathrm{~min}$ utes after the completion of the injection. Cholescintigraphy was performed under both the abdominal massage condition and a non-massage condition on different dates; in the cholescintigraphy under abdominal massage condition, an abdominal massage was performed intermittently for 90 minutes during cholescintigraphy. 


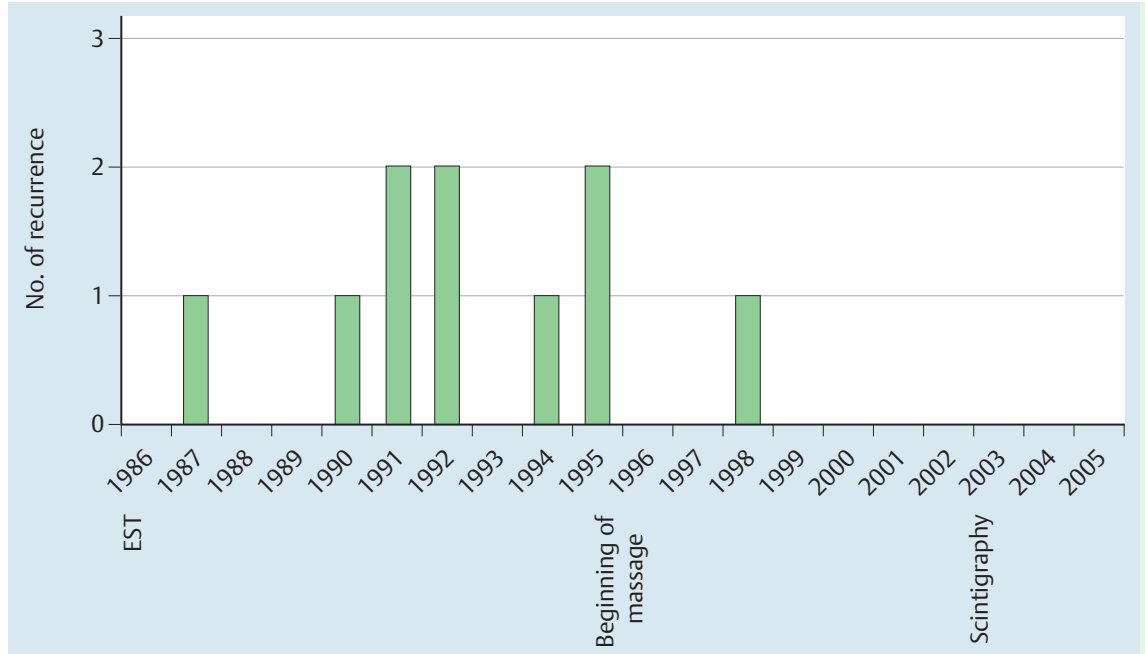

Fig. 1 Clinical course (Case 1): Bile duct stones recurred 9 times over a 10-year period after EST. Beginning in1996, daily extracorporeal abdominal massage was performed, and the bile duct stones recurred only once between 1996 and 2005.

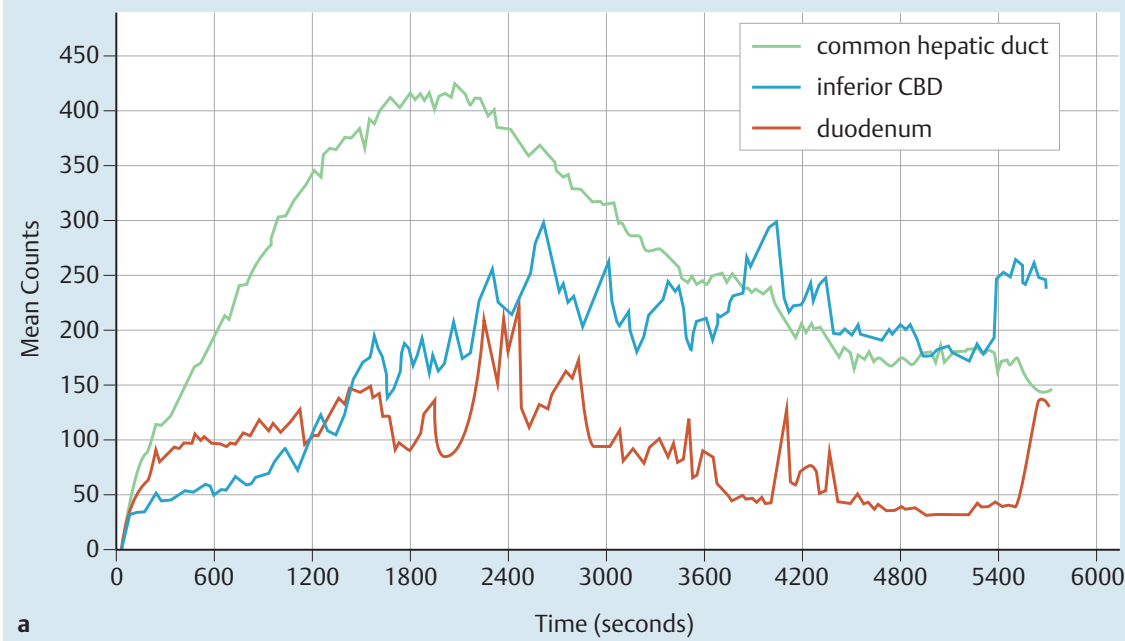

Fig. 2 Cholescintigraphy (time radioactivity curve). a Time radioactivity curve under the non-massage condition. $\mathbf{b}$ Time radioactivity curve under the massage condition. The region of interest (ROI) was plotted in the porta hepatis, the distal part of the common bile duct and the duodenum. The flow of bile into the lower common bile duct and the duodenum is promoted in panel $b$ compared to panel a. In contrast, the time radiation curve of the porta hepatis does not differ between panels $a$ and $b$.

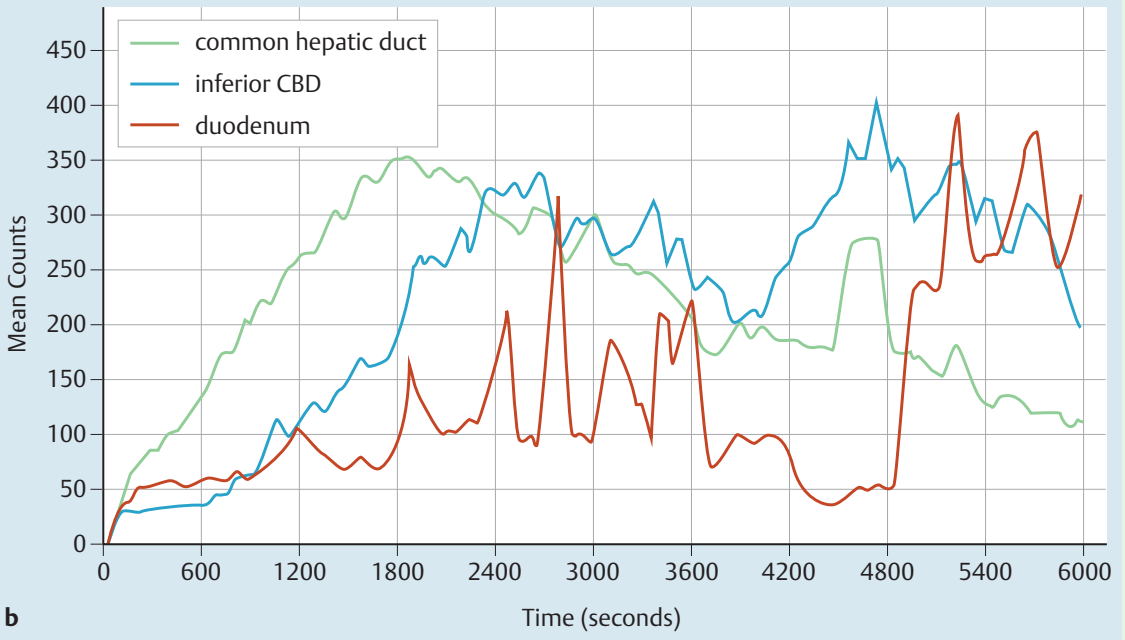

The quantitative time radioactivity curves for massage and nonmassage are shown in 6 Fig. 2. A region of interest (ROI) was plotted in the porta hepatis, the distal part of the common bile duct and the duodenum. The flow of bile into the lower common bile duct and the duodenum was promoted in the massage condition ( Fig. $\mathbf{2 b}$ ) compared to the non-massage condition ( $\bullet$ Fig. 2 a). The time radiation curve of the porta hepatis did not differ significantly between these two conditions.

\section{Patient 2}

A 60-year-old Japanese woman with a history of cholecystectomy was admitted to our hospital because of epigastric pain and back pain in March 1989. ERCP revealed a $2.5 \times 2.5-\mathrm{cm}$ bile duct stone in a dilated common bile duct (3-cm diameter.). Following EST with a large incision, the stone was extracted using a mechanical lithotripter. After this treatment in 1989, common bile duct stones recurred a total 22 times: once in 1989, twice in 1990 , four times in 1991, once in 1993, twice each in 1995 and 1996, 


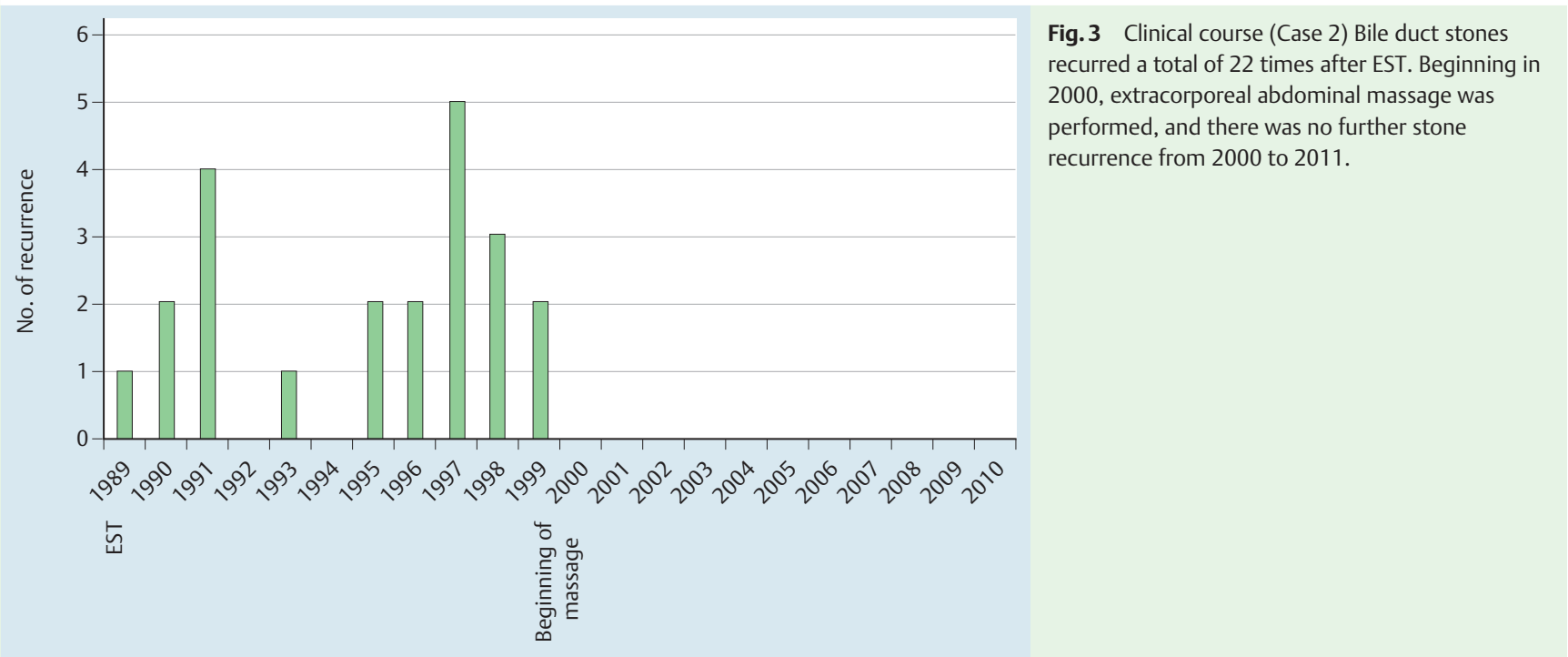

five times in 1997, three times in 1998 and twice in 1999. Stone extraction was performed endoscopically each time.

Beginning in 2000, daily extracorporeal abdominal massage was performed by the patient in the same manner as that described for Patient 1, and no further stone recurrence was noted between 2000 and 2011, when the patient stopped coming to our hospital. Her clinical course is shown in $\bullet$ Fig. 3 .

\section{Discussion}

Endoscopic treatment of common bile duct stones began with the development of EST. It was reported that compared to EST, endoscopic papillary balloon dilation (EPBD) [6] resulted in fewer recurrences of common bile duct stones, because the function of the sphincter of Oddi is expected to be better preserved with EPBD than with EST [7].

With each of the endoscopic treatments mentioned above, bile duct stone recurrence is a major problem. Ursodeoxycholic acid is administered as an oral dissolution therapy for gallbladder stones [8), but the effects of the drug in preventing recurrent bile duct stones are unknown. A randomized, controlled study [9] showed that in patients who underwent EST and the removal of bile duct stones, the addition of cholecystectomy reduced recurrent biliary events; however, at the current time, there is neither an ideal therapy that is not followed by stone recurrence nor effective drugs or therapy for the prevention of stone recurrence.

Maki [10] noted that the activity of beta-glucuronidase of bacterial origin was presumed to play an essential role in development of bile duct stones; this enzyme hydrolyzes bilirubin glucuronide into free bilirubin and glucuronic acid, and calcium in the bile combines with the carboxyl radical of liberated bilirubin to form calcium bilirubinate. Maki also noted that both stagnation and infection of bile apparently induce formation of calcium bilirubinate stones, which have been common in populations in parts of Asia.

The association between bile excretion and stone recurrence in patients who have undergone EST and stone extraction has been investigated previously using cholescintigraphy. Shimura et al. [11] reported that the recurrence rate was significantly higher in patients with delayed bile excretion compared to those without delayed bile excretion. Lai et al. [12] also reported that irrespective of the status of the gallbladder, patients with recurrent stones had a slower hepatic clearance of radioisotope during cholescintigraphy compared to patients without stone recurrence. Delayed bile excretion has been presumed to cause retrograde bacterial infections from the intestine through the abolished major papilla orifice created by the EST and to form minute stones by the above-mentioned mechanism.

In their investigation of the association between bile duct stone recurrence and gallbladder motility, Ando et al. [13] observed that patients with acalculous gallbladders were less prone to recurrence than the patients with a prior cholecystectomy and calculous gallbladders. In a study by Frossard et al. [14], the presence of the gallbladder was significantly associated with spontaneous bile duct stone passage. Normal motility of the gallbladder has been considered to wash away bile and to be related to the prevention of bile duct stone recurrence, and thus the promotion of bile excretion may prevent bile duct stone recurrences after EST.

Based on the quantitative time radioactivity curves obtained in the current study, we propose that the flow of bile into the lower common bile duct and the duodenum is promoted by abdominal massage. In contrast, the quantitative time radioactivity curves at the porta hepatis with or without massage are not different. These findings suggest that massage does not affect bile excretion from the liver to the bile duct or physically affect bile excretion from the bile duct into the duodenum. We speculate that in the 2 cases described here, excretion of bile from the bile duct to the duodenum was promoted by the patients' pressing the common bile duct from outside of the body, and we suggest that a mechanism like the washing away of bile by the gallbladder's motility prevented new stone formation or flushed out newly produced minute stones.

We suspected that the effect of the daily abdominal massage was conspicuous in our patients because of the following several factors. First, markedly delayed bile excretion was expected because our patients' common bile ducts were remarkably expanded, and their sphincter function was abolished by the EST with a large incision. Second, the patients did not have the mechanism of gallbladder motility washing away bile because they had undergone cholecystectomy. Third, the provision of pressure to the common bile duct by the massage was easy because the patients were lean 
and had poor abdominal muscle tone. Patients with these characteristics are presumed to be good candidates for the massage therapy.

Because frequent endoscopic treatments raise not only the frequency of bile duct stone recurrence but also secondary risks such as aspiration pneumonia and exacerbation of underlying disease, the development of an effective method for preventing stone recurrence is greatly desired. Further studies are needed to confirm the efficacy of abdominal massage for the prevention of recurrent bile duct stones after EST; however, the current cases suggest that abdominal massage may be helpful in preventing post-EST recurrent biliary stones.

\section{Competing interests: None}

\section{References}

1 Kawai K, Akasaka Y, Murakami K et al. Endoscopic sphincterotomy of the ampulla of Vatre. Gastrointest Endosc 1974; 20: 148-151

2 Classen M,Demling L. Endoskopische Sphinkterotomie der Papilla Vateri und Steinextraktion aus dem Ductus Choledochus. Dtsch Med Wschr 1974; 99: 496-497

3 Freeman ML, Nelson DB, Sherman S et al. Complications of endoscopic biliary sphincterotomy. N Engl J Med 1996; 335: 909-918

4 Wistow BW, Subramanian G, Heertum RL et al. An evaluation of ${ }^{99 \mathrm{~m} T c-}$ labeled hepatobiliary agents. J Nucl Med 1977; 18: 455-461
5 Yamashita M, Watanabe A, Miyazaki T et al. Clinical evaluation on hepa-

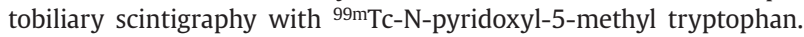
Radioisotopes 1982; 31: 657-659

6 Staritz M, Ewe K, Meyer zum Buschenfelde KH. Endoscopic papillary dilation (EPD) for the treatment of common bile duct stones and papillary stenosis. Endoscopy 1983; 15: 197-198

7 Kojima Y, Nakagawa H, Miyata A et al. Long-term prognosis of bile duct stones: endoscopic papillary balloon dilatation versus endoscopic sphincterotomy. Dig Endosc 2010; 22: 21 - 24

8 Danzinger RG, Hofmann AF, Schoenfield LJ et al. Dissolution of cholesterol gallstones by chenodeoxycholic acid. N Engl J Med 1972; 286: 1 -8

9 Lau JYW, Leow CK, Fung TMK et al. Cholecystectomy or gallbladder in situ after endoscopic sphincterotomy and bile duct stone removal in Chinese patients. Gastroenterology 2006; 130: 96-103

10 Maki T. Pathogenesis of calcium bilirubinate gallstones. Ann Surg 1966; 164: 90-100

11 Shimura J, Igarashi Y, Sakai Y. Evaluation by biliary scintigraphy of recurrence of choledocholithiasis after endoscopic sphincterotomy. Dig Endosc 2004; 16: 229-233

12 Lai KH, Peng NJ, Lo GH et al. Prediction of recurrent choledocholithiasis by quantitative cholescintigraphy in patients after endoscopic sphincterotomy. Gut 1997; 41: 399-403

13 Ando T, Tsuyuguchi T, Okugawa T et al. Risk factors for recurrent bile duct stones after endoscopic papillotomy. Gut 2003; 52: 116-121

14 Frossard JL, Hadengue A, Amouyal G et al. Choledocholithiasis: a prospective study of spontaneous common bile duct stone migration. Gastrointest Endosc 2000; 51: 175 - 179 